\title{
Safety of fluoroquinolones: An update
}

\author{
L Mandell MD FRCPC ${ }^{1}$, G Tillotson MSc FRSM ${ }^{2}$
}

\section{Mandell, G Tillotson. Safety of fluoroquinolones: An update. Can J Infect Dis 2002;13(1):54-61.}

The fluoroquinolone class of antimicrobials has been in clinical use for over 13 years. During that period, some representatives of the class have been extensively prescribed, such as ciprofloxacin and levofloxacin, while others have seen minimal use and have been restricted or withdrawn, namely, trovafloxacin and grepafloxacin. Manipulation of the fluoroquinolone structure by substituting a range of moieties around the core has yielded enhanced antibacterial activity, but in some cases this has come at a price. Specific substitutions are discussed in relation to particular recognized adverse events. In the present paper, newly introduced fluoroquinolones, such as moxifloxacin and gatifloxacin, are examined in terms of anticipated class effects and recent clinical experience. These antimicrobials are associated with reactions such as diarrhea, nausea, headache and other typical antimicrobial phenomena at rates less than 5\%. New fluoroquinolone agents should be examined carefully in light of structural findings until adequate clinical data are amassed.

Key Words: Adverse events; Fluoroquinolones; Safety; Tolerability

\section{Le point sur l'innocuité des fluoroquinolones}

RÉSUMÉ : Les fluoroquinolones forment une classe d'antimicrobiens utilisés en clinique depuis plus de treize ans. Au cours de cette période, certains de ces antimicrobiens ont été prescrits souvent, comme la ciprofloxacine et la lévofloxacine, tandis que d'autres ont été peu utilisés, ont fait l'objet d'un usage restreint ou ont été retirés du marché, à savoir la trovafloxacine et la grépafloxacine. La manipulation de la structure des fluoroquinolones par la substitution de certaines fractions de molécule situées autour du noyau a favorisé un accroissement de l'activité antibactérienne, mais non sans nocuité dans certains cas. Certaines substitutions associées à certaines réactions défavorables reconnues soulèvent des discussions. Il sera question, dans le présent article, des nouvelles fluoroquinolones, comme la moxifloxacine et la gatifloxacine, quant aux effets de classe prévus et à l'expérience clinique récente. Ces antimicrobiens sont associés à des réactions comme la diarrhée, les nausées, les céphalées et à d'autres manifestations typiques de l'utilisation de ces médicaments, et ce, à des taux inférieurs à $5 \%$. Les nouvelles fluoroquinolones devraient faire l'objet d'études approfondies à la lumière des résultats liés à leur structure jusqu'à ce qu'on ait recueilli suffisamment de données.

${ }^{1}$ Division of Medicine, McMaster University, Henderson Site, Hamilton, Ontario; ${ }^{2}$ Public Health Research Institute, New York, New York, New York USA

Correspondence: Dr LA Mandell, McMaster University, Henderson Site, 711 Concession Street, Hamilton, Ontario L8V $1 \mathrm{C} 3$.

Telephone 905-574-8520, fax 905-389-0108, Imandell@mcmaster.ca

Received for publication February 28, 2001. Accepted June 21, 2001. 
lthough nalidixic acid had limited antibacterial activi-

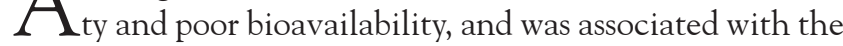
rapid development of bacterial resistance, its synthesis led to the evolution of the fluoroquinolones. The congeners of nalidixic acid are also synthetic antimicrobials that have a broad spectrum of antimicrobial activity, good absorption from the gastrointestinal (GI) tract, a unique mechanism of action resulting in the inhibition of bacterial DNA gyrase and topoisom-erase IV, favourable pharmacokinetic properties, and a good safety profile (1). Since the initial description of nalidixic acid in 1962 (2), more than 10,000 analogues have been synthesized, resulting in the addition of a fluorine atom at position 6 of the basic molecule and other molecular substitutions at positions 1, 5, 7 and 8 (3) (Figure 1). Currently, five fluoroquinolones are approved for clinical use in Canada, with others still in the investigational phase (Table 1).

The early fluoroquinolones - norfloxacin, ciprofloxacin, and ofloxacin - demonstrated excellent activity against a broad range of Gram-negative pathogens and achieved high concentrations in the urinary tract. They have emerged as effective therapies for urological infections, including uncomplicated and complicated urinary tract infection, prostatitis and pyelonephritis $(4,5)$. Additionally, ciprofloxacin's antipseudomonal activity led to this agent becoming a mainstay of hospital Gram-negative therapy.

However, these early fluoroquinolones were marginally active in vitro against some Gram-positive pathogens, particularly Streptococcus pneumoniae. Against this background emerged anecdotal reports of clinical failures in severe or difficult pneumococcal infections $(6,7)$, thus providing the impetus for the development of fluoroquinolones with improved activity against $S$ pneumoniae and other Grampositive organisms. Furthermore, some of these new variations possessed significant antianaerobic activity and many had superior pharmacokinetics.

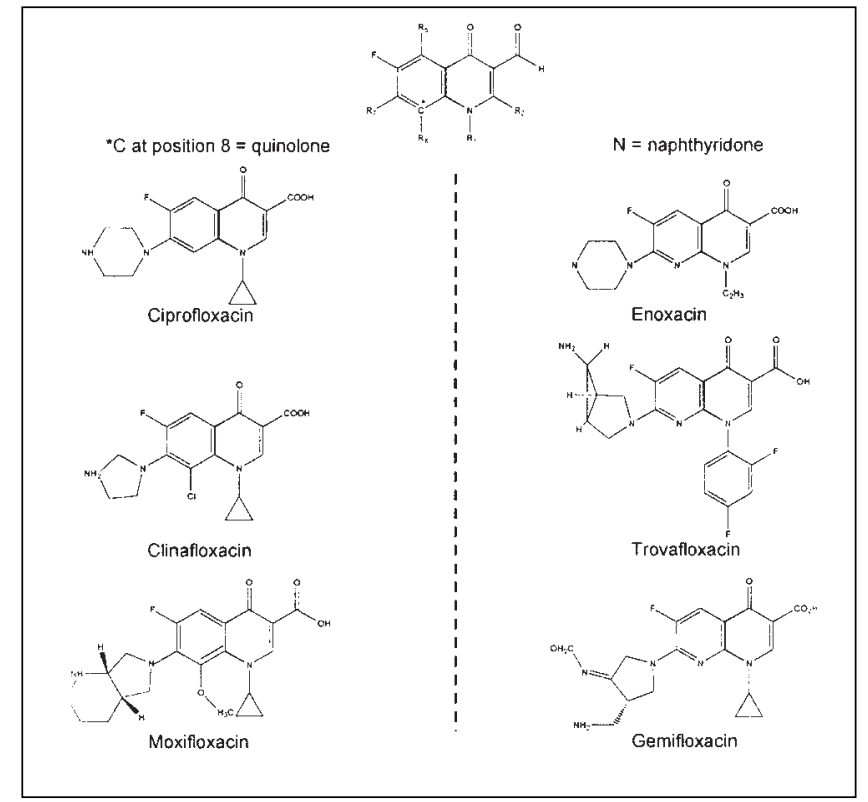

Figure 1) Analogues of the basic fluoroquinolone molecule

Clear differences in the safety and tolerability of these agents are well recognized. For example, temafloxacin was withdrawn from use in June 1992 (8), the use of trovafloxacin was restricted to the treatment of only serious infections in June 1999 (9), and grepafloxacin was withdrawn globally in October 1999 (10). The safety profiles of these three drugs represent a significant divergence from other agents in this class. Consequently, fluoroquinolones cannot be considered interchangeable in terms of efficacy or tolerability and safety (11). In fact, concern has grown regarding the potential safety issues, with recently introduced drugs and those under current investigation. Assessment of the relationship between the molecular structure and the pathophysiological mechanisms of toxic

TABLE 1

Fluoroquinolones approved in Canada

\begin{tabular}{|c|c|c|c|}
\hline Fluoroquinolone & $\begin{array}{l}\text { Canadian } \\
\text { trade name }\end{array}$ & Formulations & Comments \\
\hline Norfloxacin & $\begin{array}{l}\text { Noroxin } \\
\text { (Merck Frosst) }\end{array}$ & - $400 \mathrm{mg}$ tablets & - Limited to urinary tract infections \\
\hline Ciprofloxacin & $\begin{array}{l}\text { Cipro } \\
\text { (Bayer) }\end{array}$ & $\begin{array}{l}\text { - } 100,250,500,750 \mathrm{mg} \text { tablets } \\
\text { - IV infusion } 200 / 400 \mathrm{mg} \\
\text { - } 5 \%, 10 \% \text { suspension ear drops }\end{array}$ & $\begin{array}{l}\text { Broadest range of indications, still only } \\
\text { truly oral antipseudomonal agent }\end{array}$ \\
\hline Ofloxacin & $\begin{array}{l}\text { Floxin } \\
\text { (Janssen-Ortho) }\end{array}$ & $\begin{array}{l}\text { - 200, } 300400 \text { mg tablets } \\
\text { - Iv solutions ( } 4 \mathrm{mg} / \mathrm{mL}, 50 \mathrm{~mL})\end{array}$ & - Tends to be used for urinary tract infections \\
\hline Levofloxacin & $\begin{array}{l}\text { Levaquin } \\
\text { (Janssen-Ortho) }\end{array}$ & $\begin{array}{l}\text { - } 250,500,750 \mathrm{mg} \text { tablets } \\
\text { - IV infusion } 500 \mathrm{mg} / 100 \mathrm{~mL} \\
\text { or } 250 \mathrm{mg} / 50 \mathrm{~mL}\end{array}$ & $\begin{array}{l}\text { - L-isomer of ofloxacin is more potent part } \\
\text { - Levofloxacin is only quinolone with FDA-approval } \\
\text { for the treatment of DRSP }\end{array}$ \\
\hline Moxifloxacin & $\begin{array}{l}\text { Avelox } \\
\text { (Bayer) }\end{array}$ & - $400 \mathrm{mg}$ tablets & $\begin{array}{l}\text { - Highest activity versus Streptococcus pneumoniae } \\
\text { anaerobes and typicals, short course for AECB }\end{array}$ \\
\hline
\end{tabular}

AECB Acute exacerbation of chronic bronchitis; DRSP Drug-resistant Streptococcus pneumoniae; FDA United States Food and Drug Administration; IV Intravenous. 
effects should facilitate the understanding and prediction of fluoroquinolone-related adverse drug reactions.

The following discussion provides an overview of the safety and tolerability of fluoroquinolones. Some of the recently developed fluoroquinolones, such as moxifloxacin and gatifloxacin, are indicated for the treatment of respiratory tract infections because of the improved Gram-positive activity that is seen with gatifloxacin, as well as the additional anaerobic activity that is seen with moxifloxacin. Their safety profiles, based on clinical trials and actual empirical use, are examined. Possible explanations for the differing safety profiles of the fluoroquinolones are discussed, with a focus on molecular structure.

\section{FLUOROQUINOLONE SAFETY: AN OVERVIEW}

The fluoroquinolones as a class are generally well tolerated; most adverse effects are mild in severity, self-limiting and rarely result in treatment discontinuation (11). The most commonly occurring class effects are GI upset (nausea, vomiting, diarrhea, constipation and abdominal pain; less than $7 \%$ total). Less common effects may include central nervous system (CNS) events (less than 5\%), blood disorders (approximately 5\%), renal disturbances (approximately $4.5 \%$ ), and skin hypersensitivity amd photosensitivity effects (approximately 2\%) (12) (Table 2). Rare occurrences of convulsions, psychosis and tendinitis have also been reported (12). However, some of these events may not be directly attributable to fluoroquinolone therapy per se, and other underlying conditions of the patient, including additional drug therapy unrelated to the antimicrobial, may contribute to the reporting of side effects. Furthermore, phototoxicity, which is seen most often with lomefloxacin (13), sparfloxacin (14) and clinafloxacin therapy (15), is a dose-dependent phenomenon that requires exposure to direct or indirect ultraviolet A (UVA) light (16), and is linked most closely to the presence of a halide at the C-8 position.

Serious toxic effects have developed with the use of three agents: temafloxacin, grepafloxacin and trovafloxacin. The 'temafloxacin syndrome' was characterized by hemolytic anemia, renal impairment, hepatotoxicity, disseminated intravascular coagulation and hypoglycemia (17). Nearly two-thirds of the patients with temafloxacin syndrome developed acute renal failure. In addition, mild hepatobiliary changes were observed in one-half of the patients and coagulopathy in one-third. The development of these adverse drug reactions resulted in the withdrawal of temafloxacin from the market in June 1992, within six months of the drug receiving United States Food and Drug Administration (FDA) approval (18).

The adverse effects of temafloxacin, which were not evident in developmental clinical trials, were observed at a rate of one of every 3500 patients during postmarketing surveillance. In contrast, adverse effects similar to those seen with temafloxacin were rarely reported for ciprofloxacin. This is significant considering that ciprofloxacin has the
TABLE 2

Adverse reactions associated with fluoroquinolones

\begin{tabular}{lc}
\hline Adverse reaction & $\begin{array}{c}\text { Range } \\
\text { of incidence (\%) }\end{array}$ \\
\hline Gastrointestinal (diarrhea, vomiting) & $0.8-6.8$ \\
Central nervous system & $0.9-11$ \\
$\quad$ (dizziness, headache) & \\
Skin (rashes) & $0.4-2.1$ \\
Blood disorders & $0.5-5.3$ \\
Cardiovascular (palpitations) & $0.5-2.0$ \\
Musculoskeletal & $0.5-2.0$ \\
Phototoxicity or photoallergy & $0.5-2.1$ \\
Serious reactions, eg, hemolytic & $<0.5$ \\
$\quad$ uremic syndrome, Stevens Johnson & \\
$\quad$ syndrome & \\
\hline
\end{tabular}

Adapted from reference 12

largest database of safety information of all the fluoroquinolones (from over 80,000 patients in clinical studies and more than 280 million prescriptions dispensed). Further analysis of these specific 'temafloxacin events' showed findings for norfloxacin and ofloxacin that were similar to those for ciprofloxacin (17). Specifically, these effects were seen in only one of every 17,000 ciprofloxacintreated patients, one of every 25,000 patients who received norfloxacin and one of every 33,000 ofloxacin-treated patients (19).

Grepafloxacin, which was introduced to the market in August 1997, was withdrawn voluntarily from use in October 1999 due to reports of severe cardiovascular events among patients taking the drug (10). The serious cardiovascular events that were associated with grepafloxacin therapy became evident only after broad clinical use. Seven patients were observed to experience Torsade de Pointes from an estimated 3.7 million patients who received grepafloxacin from the time of its introduction to clinical use to its withdrawal in late 1999 (10).

Trovafloxacin was approved based on findings from equivalency-based clinical efficacy studies encompassing more than 6000 trovafloxacin-treated patients. In these studies, $5 \%$ of patients discontinued therapy because of adverse effects; the most frequently reported events involved the CNS and GI tract (20). As with temafloxacin, the toxic effects of trovafloxacin were not evident until after the drug was in widespread clinical use. Serious adverse events associated with the use of trovafloxacin, including hepatic eosinophilia and hypoglycemia (21), were identified during postmarketing surveillance after 2.5 million patients had been exposedto the drug. These events resulted in the United States and Canada restricting drug's use to the hospital (health care facility)-based treatment of serious life-or limb-threatening infections (9).

While the withdrawal of temafloxacin and grepafloxacin from the market and the significantly restricted use of trovafloxacin raise concerns about fluoroquinolone safety, it 
is necessary to recognize several important issues when assessing its efficacy and safety. Despite rigorous preclinical drug investigation, once a drug is introduced into widespread clinical practice, the likelihood of observing potentially rare but serious side effects is increased significantly (21). For example, in the 18 months from approval to restriction, approximately 2.5 million trovafloxacin prescriptions were written, which represented an increase in patient exposure of more than 400 -fold over that of the clinical dossier study (9). However, this differs from the case of temafloxacin, in which serious adverse events were observed much earlier and with significantly fewer patients, approximately 180,000.

A class reaction is an effect that can be attributable solely to the drug in question or related to other factors (22). An understanding of the pathophysiological mechanism(s) of these adverse effects may help to clarify and explain some adverse reactions. Moreover, it is important to recognize the low incidence of side effects and significant adverse events in other agents in the class, which generally demonstrates the relative safety of this class of drugs (11).

\section{EVALUATING SAFETY AND ANTIMICROBIAL ACTIVITY PROFILES BASED ON MOLECULAR STRUCTURE}

Potential reactions to fluoroquinolones may be predicted on the basis of differing molecular structures in this class. Such effects include GI, CNS and skin or cutaneous events. All fluoroquinolones are analogues of the basic quinolone pharmacore (Figure 1), and distinct antimicrobial and pharmacological activities have been defined for each modification in the molecular structure (3). Similarly, specific structural-sideeffect relationships may also help to explain some of the adverse effects that have been observed with each drug (23) (Figure 2).

The first alterations in the quinolone molecule included the addition of a fluorine atom at the 6-position and a piperazinyl moiety at the 7 -position. These modifications resulted in the introduction of norfloxacin and ciprofloxacin, which offered a significantly broader spectrum of activity than that of nalidixic acid (23). The structure of ciprofloxacin differs from that of norfloxacin by the addition of a cyclopropyl ring at the 1-position, which is considered necessary for optimal Gram-negative activity $(3,23)$. Ofloxacin and its active L-isomer levofloxacin are examples of 1,8-cyclo (N1 to C8 bridged) compounds. Both have an $N$-methyl piperazinyl moiety at the $\mathrm{C} 7$ position of a tricyclic benzoxazine nucleus. Similar to ciprofloxacin, these alterations in the base quinolone pharmacore resulted in enhanced Gram-negative activity, some activity against Gram-positive pathogens and improved pharmacokinetics. Furthermore, there is a lower potential for drug interaction with theophylline and other P450 metabolized compounds (3).

A C5-amino group substituent improves both Grampositive and Gram-negative activity in the presence of $\mathrm{N} 1$ cyclopropyl. This improved activity is dependent on the C8 substituent and is most effective when this substituent is a

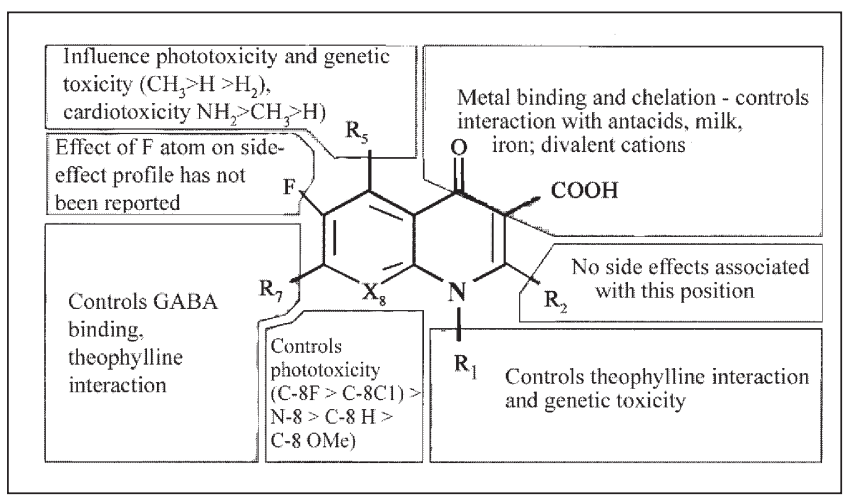

Figure 2) Structure of adverse reaction relationships of fluoroquinolone. Adapted from reference 3

halide, as is the case with sparfloxacin (24). Sparfloxacin also bears two cis-oriented methyl groups on the piperazinyl moiety. The cis-dimethyl substitution has been shown to increase in vivo antimicrobial potency, especially against Gram-positive organisms (25).

Selected agents among the most recently developed fluoroquinolones have demonstrated enhanced activity against Gram-positive organisms and anaerobes, eg, moxifloxacin. Their use may be more appropriate against respiratory tract and intra-abdominal pathogens (1). Again, their modified molecular structure may provide some insight regarding potential adverse effects and antimicrobial activity. Compared with ciprofloxacin, moxifloxacin and gatifloxacin have an additional methoxy side chain at C-8; moxifloxicin is differentiated further by a bulky, lipophilic azabicyclo modification at C-7, which increases activity against Gram-positive bacteria and reduces susceptibility to efflux pumps (26). Clinafloxacin bears a pyrrolidine ring at the 7-position, which also enhances activity against Gram-positive bacteria (3). Alkyl substitution of either the piperazine or pyrrolidine ring - for example, moxifloxacin, gatifloxacin, levofloxacin and sparfloxacin improves solubility (which, in turn, may decrease the risk for crystalluria), enhances the activity against Gram-positive bacteria, and prolong the drugs' half-life (Figure 2) (3).

\section{CATEGORIZED ADVERSE EFFECTS}

Many of the class side effects of fluoroquinolones are associated with modifications of the quinolone pharmacore at the 1-, 7- and 8-positions (Figure 2). The following discussion focuses on these specific class effects with respect to structural modifications at the 1-, 7-and 8-positions.

\section{CNS effects}

Although much about the pathophysiology of fluoroquinolone-related CNS effects remains ill defined, one hypothesis suggests that drug interactions with the gammaaminobutyric acid receptor (GABAa), an inhibitory neurotransmitter, may explain CNS-stimulating effects. The R7 side chain substituent, particularly unsubstituted piperazinyl and pyrrolidinyl moieties (Figure 2), appears to dic- 
tate affinity for the GABA receptor. Thus, those agents with an unsubstituted piperazinyl ring (ciprofloxacin, enoxacin and norfloxacin) demonstrate high-affinity binding to GABAa and interfere with GABA binding to its receptor (24).

Furthermore, biphenyl acetic acid, an active metabolite of the nonsteroidal anti-inflammatory drug fenbufen, has been shown to enhance the binding of fluoroquinolones to GABA receptors (24). Coadministration of fenbufen and a fluoroquinolone has been shown to induce convulsive seizures in mice; yet, some investigators note that quinolone-mediated alterations in GABA receptor binding are weak and cannot fully explain these CNS effects (24). Furthermore, seven Japanese patients developed seizures as a result of taking enoxacin and fenbufen together (personal communication, Y Niki).

Studies have also shown that CNS penetration by quinolones does not appear to correlate with the reported incidence of CNS effects (27). A possible reconciliation of these discrepancies is that fluoroquinolones can also induce excitatory effects through direct activation of $\mathrm{N}$-methyl-Daspartate (NMDA) and adenosine-receptor mechanisms. Thus, it may be that only under specific conditions of sufficient CNS penetration, coupled with threshold antagonism of inhibitory pathways (GABA) and stimulation of excitatory pathways (NMDA, adenosine), that observable CNS symptoms are manifested.

Ofloxacin and its L-isomer, levofloxacin, have been observed to induce a range of CNS-related adverse reactions, including headaches (9\% ofloxacin, 6\% levofloxacin), dizziness (5\% ofloxacin, 3\% levofloxacin), and less common events include confusion, impaired thinking, insomnia and rarely psychosis. These reactions have been induced even in the absence of concomitant drugs such as nonsteroidal anti-inflammatory drugs (28). These reactions tend to occur more frequently with ofloxacin than with levofloxacin.

CNS effects associated with quinolones range from the trivial to severe (dizziness to convulsions) (29), and vary among class members. For instance, with trovafloxacin, dizziness is the most frequently reported adverse event at $19 \%$ (30); however, with other new agents, dizziness is less common (moxifloxacin 2.9\% [31], gatifloxacin 3\% [32], gemifloxacin 2.8\% [33]).

\section{Photosensitivity}

Two types of photosensitivity reactions have been associated with fluoroquinolone therapy: photoallergic reactions ,and phototoxic responses. Photoallergic reactions are rare and require previous exposure to a drug in the fluoroquinolone class. In contrast, phototoxic responses are more common and can develop without previous exposure to a fluoroquinolone if the dose of the photolabile drug and exposure to UVA light (around 350 to $360 \mathrm{~nm}$ ) are sufficiently high, as demonstrated by the use of some fluoroquinolones in a murine model (Table 3) $(33,34)$. Halogenation at the C-8 position is responsible for many of
TABLE 3

Fluoroquinolone phototoxity relationship to C-8 moiety

\begin{tabular}{lcc}
\hline Fluoroquinolone & C-8 moiety & $\begin{array}{c}\text { Highest 'no effect } \\
\text { dose' }(\mathbf{m g} / \mathbf{k g})\end{array}$ \\
\hline Norfloxacin & $\mathrm{C}-\mathrm{H}$ & $>300$ \\
Ciprofloxacin & $\mathrm{C}-\mathrm{H}$ & $>300$ \\
Ofloxacin & $\mathrm{C}-\mathrm{OR}$ & $>300$ \\
Moxifloxacin & $\mathrm{CH}_{3} \mathrm{OH}$ & $>300$ \\
Gatifloxacin & $\mathrm{CH}_{3} \mathrm{OH}$ & $>100$ \\
Gemifloxacin & $\mathrm{N}$ & $>100$ \\
Trovafloxacin & $\mathrm{N}$ & $>100$ \\
Enoxacin & $\mathrm{N}$ & 100 \\
Sparfloxacin & $\mathrm{CF}$ & 18 \\
Lomefloxacin & $\mathrm{CF}$ & 10 \\
Bay y 3118 & $\mathrm{CF}$ & 10 \\
Clinafloxacin & $\mathrm{CF}$ & 10 \\
\hline
\end{tabular}

the photosensitivity reactions that occur during fluoroquinolone treatment (3). Some of the fluoroquinolones induce mild photosensitivity reactions, such as erythema of sun-exposed skin, with varying frequency; however, drugs such as lomefloxacin and sparfloxacin with a C-8-fluorine substituent and clinafloxacin with a C8-chlorine substituent, exhibit a greater incidence of phototoxic reactions than do drugs without this substituent (3). Corroboration of the halogen effect was provided by the marked phototoxicity of Bay 3118 compared with the virtual absence of such an effect with the use of moxifloxacin. The molecules are identical save for C-8 chlorine on Bay 3118 and a methoxy on moxifloxacin (35). The investigators concluded that moxifloxacin has almost no phototoxic potential.

Photosensitivity reactions are postulated to occur as a result of fluoroquinolone photodegradation, and the molecule's ability to generate free monovalent oxygen radicals. In turn, these oxidative radicals may attack cellular lipid membranes, initiating inflammatory processes and eventually resulting in DNA damage (28). Evidence for photoinduced oxidative DNA damage is demonstrated by the development of tumours in mice treated with lomefloxacin (36).

\section{Genetic toxicity}

Quinolones have been shown to inhibit mammalian cellular topoisomerase II, which correlates with in vitro cytotoxicity in those cells (3). Substitutions at the 1-, 7- and 8 -positions have the greatest potential for cytotoxicity, with the effect being additive. However, disruption of the chromosome, or clastogenicity, usually occurs only at very high drug concentrations (300 to 10,000 times the normal dose level), and postmarketing surveillance studies have not found any carcinogenic potential linked to fluoroquinolone use. 
TABLE 4

Reported QT prolongation (ms) with four new fluoroquinolones

\begin{tabular}{lccc}
\hline Drug & Sample size & $\begin{array}{c}\text { QT }_{c} \\
\text { prolongation }\end{array}$ & Reference \\
\hline Moxifloxacin & 2650 patients & 6 & 30 \\
Levofloxacin & 21 patients & 4.3 & 44 \\
Gatifloxacin & 55 volunteers & 2.9 & 41 \\
Gemifloxacin & 121 patients & 5.1 & 42 \\
\hline
\end{tabular}

\section{Cardiovascular effects}

Cardiovascular effects, particularly prolongation of the QT interval corrected for heart rate (QT interval), have been reported with quinolone therapy (22). Notably, sparfloxacin increased the $\mathrm{QT}_{\mathrm{c}}$ interval in up to $3 \%$ of patients (37). The significance of this finding may relate to the severe cardiac events that result in the withdrawal of grepafloxacin. It is recommended that sparfloxacin not be administered to patients with known $\mathrm{QT}_{\mathrm{c}}$ interval prolongation or to patients receiving concomitant pharmacotherapy that might increase the interval, induce bradycardia or promote Torsade de pointes (for example, class Ia and III antiarrhythmics, bepridil, cisapride, erythromycin, terfenadine or tricyclic antidepressants). It appears that this effect may be more predictable with medications that are co-administered with quinolones that inhibit cytochrome P450-mediated metabolism due to increased drug accumulation. To date, no specific structural modification has been associated with cardiovascular effects, including those that might influence cytochrome P450-mediated metabolism. Currently, the only possible specific structural modifications that may be associated with the increased incidence of serious cardiovascular events associated with grepafloxacin and sparfloxacin therapy are a methyl or amino moiety at the C-5 position (grepafloxacin and sparfloxacin, respectively), although Phase III clinical studies did show associated $\mathrm{QT}_{\mathrm{c}}$ prolongation (22).

In light of the experience with sparfloxacin and grepafloxacin with respect to cardiovascular effects, more recent class members have been investigated to varying degrees, which is further highlighted by a recent report of a levofloxacin-associated ventricular tachycardia (38). In the opinion of the FDA, the investigations of moxifloxacin set a new standard in drug development (39). More than 2600 patients in clinical trials had paired, timed electrocardiogram evaluations that revealed a mean $\mathrm{QT}_{\mathrm{c}}$ prolongation of $6 \mathrm{~ms}$ for moxifloxacin, at a 2.8\% frequency of the European Medicines Evaluation Agency - significant $\mathrm{QT}_{\mathrm{c}}$ changes. The comparable figures for the comparator agents were $1 \mathrm{~ms}$ and 2.2\%; more specifically for clarithromycin $2 \mathrm{~ms}$ and $3.7 \%$. (31). Extensive analyses of the $\mathrm{QT}_{\mathrm{c}}$ phenomena with levofloxacin (40), gatifloxacin (41) and gemifloxacin (42) have either not been completed or reported. Table 4 shows the reported $\mathrm{QT}_{\mathrm{c}}$ prolongation data that is currently available.
TABLE 5

\begin{tabular}{lccc}
$\begin{array}{l}\text { Cumulative drug discontinuation rates for some new } \\
\text { fluoroquinolones }\end{array}$ & $\begin{array}{c}\text { Drug } \\
\text { discontinuation } \\
\text { rate (\%) }\end{array}$ & $\begin{array}{c}\text { Various } \\
\text { comparators (\%) }\end{array}$ & References \\
\hline Quinolone & 3.7 & Not given & $\mathrm{Pl}$ \\
\hline Levofloxacin & 3.3 & 3.2 & 30 \\
Moxifloxacin & 2.9 & Not given & 31 \\
Gatifloxacin & 3.2 & 2.2 & 32 \\
Gemifloxacin & 3.2 &
\end{tabular}

PI Product information

Analysis of clinical trial and postmarketing data for moxifloxacin, encompassing over ten million patients, has revealed three cases of Torsade de Pointe, including an 83. year-old woman with a complex cardiological and pharmacological history, whose $\mathrm{QT}_{\mathrm{c}}$ interval was prolonged from 490 to $520 \mathrm{~ms}$. The patient was successfully cardioverted. The two other cases were similar 'at risk' patients, ie, elderly, female, prior history of cardiac disease and various concomitant medications (Bayer AG, data on file). The incidence of significant ventricular tachyarrhythmias and torsade de pointes appears to be a class phenomenon, but at a rate that is similar to normal background reports (43).

\section{Tendon and tendonitis}

Rupture of tendons or tendonitis is a rare event associated with fluoroquinolones (44). Such events tend to affect the Achilles tendon, and are bilateral in $50 \%$ of cases. Predisposing factors are reported often, which can include corticosteroid therapy, renal disease, hemodialysis and transplantation $(45,46)$. Usually symptoms resolve within weeks, but in a small proportion of patients, they may persist for months.

This problem was originally observed with pefloxacin, but has subsequently been reported with almost all class members. The reason for such an unusual event may be related to the serum concentrations of magnesium; low levels precipitate joint and tendon problems in animal models (47). Concomitant administration of corticosteroids and quinolones, especially in the elderly, is contraindicated.

\section{Hepatic toxicity}

The toxic effects associated with the use of temafloxacin and trovafloxacin therapy have not been definitively ascribed to specific molecular structure modifications. Investigators have hypothesized that increased halogenation, or a toxic metabolite, is the cause of the temafloxacin syndrome (18). The pathophysiology of adverse hepatic events (trovafloxacin) and hypogylcemia (trovafloxacin and temafloxacin) remains unknown. It has been suggested that the addition of a 2,4-difluorophenyl moiety at C-1 may be the culprit for the toxic effects associated with both of these agents, although no definitive evidence has proved this. A proposed mechanism suggests that this component may be metabolically cleaved off and may then act as a hapten, triggering an 
TABLE 6

Comparison of adverse drug reactions associated with some approved fluoroquinolones (\%)

\begin{tabular}{|c|c|c|c|c|c|c|c|}
\hline Reaction & Levofloxacin & & Gatifloxacin & & & xifloxac & \\
\hline Reference & $\mathrm{PI}$ & $50^{*}$ & 51 & 31 & $30^{*}$ & 51 & 52 \\
\hline No patients & NR & 2252 & 1655 & 15,625 & 6170 & 6500 & 18,409 \\
\hline Nausea & 7.1 & 9 & 2.8 & 4 & 8 & 0.3 & 5.7 \\
\hline Diarrhea & 5.6 & 4 & 1.7 & 1.4 & 6 & 0.9 & 2.4 \\
\hline Headache & 6.4 & 4 & 0.5 & 0.9 & 2 & 0.1 & $<2$ \\
\hline Vomiting & 2.2 & 2 & 0.6 & 0.7 & 2 & 0.2 & $<1$ \\
\hline Vaginitis & 1.6 & 5 & $<1$ & $<1$ & $<1$ & $\mathrm{NI}$ & $<1$ \\
\hline Dizziness & 2.9 & 3 & 1.3 & NR & 3 & 0.3 & 2.3 \\
\hline Taste perversion & 1.0 & 2 & 0.8 & 0.5 & $<1$ & NR & $<1$ \\
\hline Discontinuations & 3.4 & 3.2 & NR & 3.1 & NR & NR & NR \\
\hline
\end{tabular}

${ }^{*}$ Clinical trial programs. PI Package Insert trial data; NI No incidence; NR Not reported

array of unusual immunological sequelae, including hepatic eosinophilia (personal communication, AP Ball).

\section{DISCONTINUATIONS}

With the advent of modern drug development, the solicitations and subsequent reporting of adverse events has seemingly revealed major problems with new agents in comparison with older members of the same class. Consequently, it may be a more valid assessment of a drug's tolerability if discontinuation of therapy is compared. Unfortunately, few companies report the specific reasons for drug discontinuation but merely report the cumulative rates. Some of the known discontinuation rates are: levofloxacin 3.7\%; moxifloxacin 3.3\%; gatifloxacin 2.9\% (48); and gemifloxacin 3.2\% (Table 5) (31-33).

\section{POSTMARKETING SURVEILLANCE}

Class effects of the fluoroquinolones continue to be observed; these include upper GI effects, CNS disorders, tendonitis and phototoxicity. Recent studies have highlighted $\mathrm{QT}_{\mathrm{c}}$ prolongation as another probable class effect (22), although the clinical significance of these findings is still uncertain. Within the past year, other effects have been reported which may be class phenomena, eg, anaphylaxis, hepatic reactions (trovafloxacin) and severe cutaneous rashes (gemifloxacin) (49). However, as diligent surveillance of newly marketed compounds continues, millions of patients who have been treated with fluoroquinolones should provide the database to confirm the class nature, or not, of the new events. Current postmarketing surveillance data of over ten million moxifloxacin- (43, personal communication, C Reiter) and over three million gatifloxacintreated patients (personal communication, S Nicholson) have not shown any notable adverse events, including the typical or predicted class effects (Table 6).

\section{SUMMARY}

The use of fluoroquinolones has advanced the treatment of genitourinary, various nosocomial and, most recently, com- munity respiratory infections through greater antimicrobial coverage. Generally, these drugs are well tolerated and have proven to be safe and efficacious antimicrobial agents. Fluoroquinolones continue to be contraindicated for pregnant women; however, a growing body of evidence suggests that these drugs are safe in children. The concern now is not with toxicity in the paediatric age group, but with the rapid emergence of resistance to this class of compounds should these agents be widely used in children.

Adverse effects associated with several substituents that have been added to the quinolone pharmacore have been identified. The structure of the quinolones with increased adverse events and/or toxicities differs from that of the established agents with proven safety. While molecular structure of a drug may predict its potential for certain adverse effects, the safety of any new drug is established by careful postmarketing surveillance. Newer fluoroquinolones with improved activity against Gram-positive pathogens (such as gatifloxacin) and anaerobes (such as moxifloxacin) will be used to treat respiratory tract infection, and the older, established drugs with maintained Gram-negative activity (such as ciprofloxacin) may remain the fluoroquinolone of choice for the treatment of urinary tract infection. Further understanding of the structure-related side effects of these drugs may improve the predictability of adverse events of new medications.

\section{REFERENCES}

1. Hooper DC. New uses for new and old quinolones and the challenges of resistance. Clin Infect Dis 2000;30:243-54.

2. Lesher GY, Froelich ED, Gruet MD, Bailey JH, Brundage RP. 1,8 naphthyridine derivatives: a new class of chemotherapeutic agents. J Med Pharm Chem 1962;5:1063-8.

3. Domagala JM. Structure-activity and structure-side-effect relationships for the quinolone antibacterials. J Antimicrob Chemother 1994;33:685-706.

4. Naber KG. Fluoroquinolones in urinary tract infections, proper and improper use. Drugs 1996;52(Suppl 2):27-33.

5. Echols RM, Heyd A, Tosiello R, Busch W, Schacht P. Efficacy and safety of ciprofloxacin for chronic bacterial prostatitis. Infect Med 1995;12:283-9. 
6. Cooper B, Lawlor M. Pneumococcal bacteremia during ciprofloxacin therapy for pneumococcal pneumonia. Am J Med 1989;87(Suppl 5A):225-7.

7. Gordon JJ, Kaufmann CA. Superinfection with Streptococcus pneumoniae during ciprofloxacin therapy. Am J Med 1990;89:383-4.

8. Blum MD, Graham DJ, McCloskey CA. Temafloxacin syndrome: A review of 95 cases. Clin Infect Dis 1994;18:946-50.

9. Pfizer relabels antibiotic Trovan for serious infections. Doctors Guide (e-mail edition), August 30, 1999. <http://www.pslgroup.com/dg/106B6.htm>

10. GlaxoWellcome voluntarily withdraws Raxar (grepafloxacin). Press Release, October 26, 1999. Available at $<$ http://www.fda.gov/medwatch/safety/1999/raxar.html> Version current at January 14, 2002

11. Ball P, Mandell L, Niki Y, Tillotson G. Comparative tolerability of the newer fluoroquinolone antibacterials. Drug Saf 1999,21:407-21.

12. Childs S. Safety of the fluoroquinolone antibiotics; focus on the molecular structure. Infect Urol 2000;13:3-10.

13. Wadworth AN, Goa KL. Lomefloxacin. A review of its antibacterial activity, pharmacokinetic properties and therapeutic use. Drugs 1991;42:1018-60.

14. Tokura Y, Iwamoto Y, Mizutani K, Takigawa M. Sparfloxacin phototoxicity: potential photoaugmentation by ultraviolet $\mathrm{A}$ and $\mathrm{B}$ sources. Arch Dermatol Res 1996;288:45-50.

15. Tack KJ, Eisemann I, Zervos M. Clinafloxacin for the treatment of serious infections caused by multiply-resistant pathogens. 6th International Symposium on New Quinalones. Denver: November 14-16, 1998. (Abst 178)

16. Paton J, Reeves DS. Clinical features and management of adverse events of quinolone antibacterials. Drug Saf 1991;6:8-27.

17. Echols RM, Oliver MK. Ciprofloxacin safety relative to temafloxacin and lomefloxacin. 18th International Congress on Chemotherapy. Stockholm, June 18-21, 1993;349-50. (Abst 27)

18. Finch RG. The withdrawal of temafloxacin; Are there implications for other quinolones? Drug Saf 1993;8:9-11.

19. Lietmann PS. Fluoroquinolone toxicities: An update. Drugs 1995;49(Suppl 2):159-63.

20. Trovafloxacin (Trovan) package insert. New York: Pfizer, 1998

21. Chen JL, MacLean JA. Trovafloxacin associated eosinophilic hepatitis. N Engl J Med 2000;342:359-60.

22. Ball P. Quinolone-induced QT interval prolongation: A not-sounexpected class effect. J Antimicrob Chemother 2000;45:557-9.

23. Tillotson GS. Quinolones: structure-activity relationships and future predictions. J Med Micro 1996;44:320-4

24. Hori S, Shimada J, Saito A. Comparison of the inhibitory effects of new quinolones on gamma-aminobutyric-acid receptor binding in the presence of anti-inflammatory drugs. Rev Infect Dis 1989;(Suppl 5):s1397-8.

25. Brighty KE, Gootz TD. The chemistry and biological profile of trovafloxacin. J Antimicrob Chemother 1997;39(Suppl B):1-4

26. Pestova E, Beyer R, Cianciotto NP, Noskin GA, Peterson LR. Contribution of topoisomerase IV and DNA gyrase in Streptococcus pneumoniae for resistance to novel fluoroquinolones. Antimicrob Agent Chemother 1999;43:2000-4

27. Bryskier A,Chantot JF. Classification and structure-activity relationships of fluoroquinolones. Drugs 1995;49(Suppl 2):16-28

28. Ball P, Tillotson GS. Tolerability of fluoroquinolone antibiotics: past, present and future. Drug Saf 1995;13:343-58.

29. Jangknecht R, Hesker YA. Development in quinolones. Bacteriology, pharmacokinetics and initial clinical experience of several investigational quinolone derivatives. Pharm Weekbl Sci 1989;11:33-43

30. Baz MN, Janetti W, Villaneuva, et al. The efficacy and tolerability of moxifloxacin compared to trovafloxacin in the treatment of acute sinusitis. Todays Therapeutic Trends 1999;17:303-19.

31. Kubin R, Reiter C. Safety update of moxifloxacin: A current review of clinical trials and post-marketing observational studies. 40th Interscience Congress on Antimicrobial Agents and Chemotherapy. Toronto, September 17 to 20, 2000. (Abst 820)

32. Von Seggern K, Russo R, Wikler MA. A novel approach to postmarketing surveillance: the Tequin experience study. 40th Interscience Congress on Antimicrobial Agents and Chemotherapy. Toronto, September 17 to 20, 2000. (Abst 2216)

33. Henkel TJ, McKay D, Young C. Safety of gemifloxacin in adult patients with respiratory and urinary infections. 3rd European Congress of Chemotherapy. Madrid, May 7 to 10, 2000. (Abst M130)

34. Gould JW, Mercurio MG, Imlets CA. Cutaneous photosensitivity diseases induced by exogenous agents. J Am Acad Dermatol 1995;33:551-71.

35. Mann I, Murphy J, Ferguson J. Fluoroquinolone photoxicity: A comparison of moxifloxacin and lomefloxacin in normal volunteers. J Antimicrob Chemother 1999;43(Suppl B):77-82.

36. Makinen M, Forbes PD, Stenback F. Quinolone antibacterials: A new class of photochemical carcinogens. J Photochem Photobiol B 1997;37:182-7.

37. Dupont H, Tinsit JF, Souweine B, Gachot B, Wolff M, Regnier B. Torsade de Pointes related to sparfloxacin. Eur J Clin Micro Infect Dis 1996;15:350-1.

38. Samaha FF. QTc interval prolongation and polymorphic ventricular tachycardia in association with levofloxacin. Am J Med 1999, 107:528-9.

39. FDA Report. Bayer Avelox cardiac safety studies recommended by FDA committee. Pink Sheet-Pres. Pharma Biotech 1999;61:4-5.

40. Iannini PB, Kramer H, Circiumaru I, Byazrova E, Doddamani S. QT prolongation associated with levofloxacin. 40th Interscience Congress on Antimicrobial Agents and Chemotherapy. Toronto, September 17 to 20, 2000. (Abst 821)

41. Tequin(gatifloxacin) package insert. Princeton: Bristol-Myers Squibb, 1999.

42. Bird N, Lewis A, Montague T, Bygate E, Dixon R. Assessment of the effect of gemifloxacin on QTc interval in healthy volunteers. 40th Interscience Congress on Antimicrobial Agents and Chemotherapy. Toronto, September 17 to 20, 2000. (Abst 821)

43. Iannini PB, Kubin R, Reiter C, Tillotson G. Reassuring safety profile of moxifloxacin. Clin Infect Dis 2001;32:1112-4.

44. Khan MF, Hayem G. Tendon and fluoroquinolones, unresolved issues. Rev Rheum 1997;64:437-9.

45. Decoq G, Moriniere P, Dufour I. [Is hemolysis a risk factor for tendinopathies due to fluoroquinolones?] Therapie 1997;52:613-4.

46. Marti HP, Stoller R, Frey FJ. Fluoroquinolones as a cause of tendon disorders in patients with renal failure/renal transplant. Br J Rheumatol 1998;37:343-4

47. Shakibaei M, Pfister K, Schwabe R, Vormann J, Stahlmann R. Ultrastructure of Achilles tendon of rats treated with ofloxacin and fed a normal or magnesium deficient diet. Antimicrob Agent Chemother 2000;44:261-6.

48. Breen J, Skuba K, Grasela D. Safety and tolerability of gatifloxacin, an advanced-generation, 8-methoxy fluoroquinolone. J Respir Dis 1999;20(Suppl S):70-6.

49. Smith Kline Beecham receives non-approval letter from FDA on Factive (gemifloxacin). http://www.sb.com. December 7, 2000.

50. Jones RN, Pfaller MA, Wikler M, Nicholson S and the TeqCES participant group. Clinical efficacy and safety of gatifloxacin in S. pneumoniae community-acquired pneumonia: initial report from TeqCES. 40th Interscience Congress on Antimicrobial Agents and Chemotherapy. Toronto, September 17 to 20, 2000. (Abst 81753)

51. Miravitles M, Ros F, Cedos A, et al. Evaluation of efficacy and safety of moxifloxacin in acute exacerbations of chronic bronchitis: A Spanish community perspective. Int J Clin Prac. (In press)

52. Whitehouse A, Brar J, Kowalsky S, Perroncel R, Haverstock D, Church D. The Avelox Clinical Experience Study, a postmarketing observational study. 1st International Conference on Resistant Gram-Positive Infections. San Antonio, December 3 to 5 , 2000. (Abst I-13) 


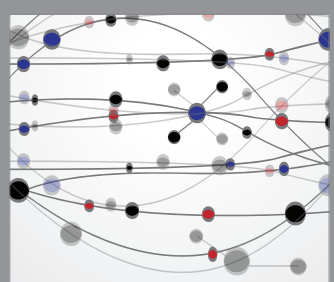

The Scientific World Journal
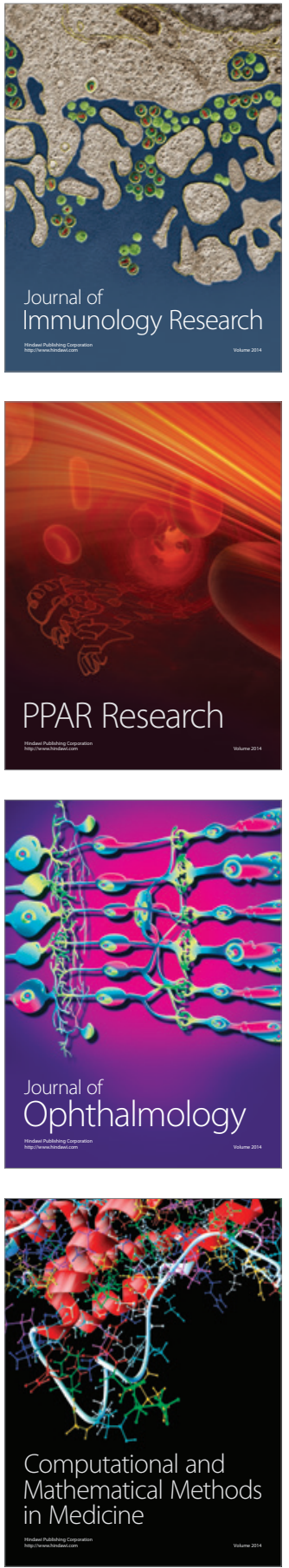

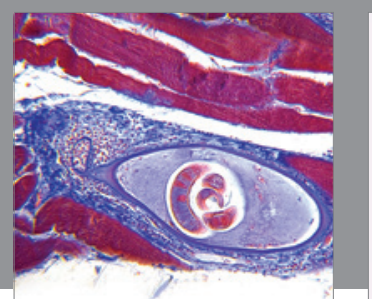

Gastroenterology Research and Practice

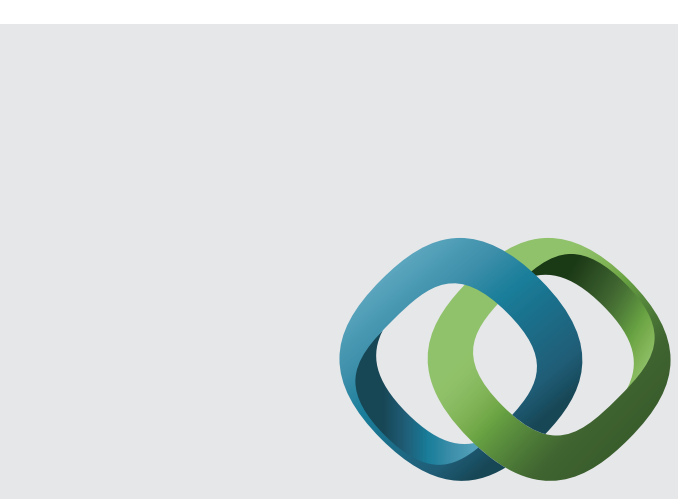

\section{Hindawi}

Submit your manuscripts at

http://www.hindawi.com
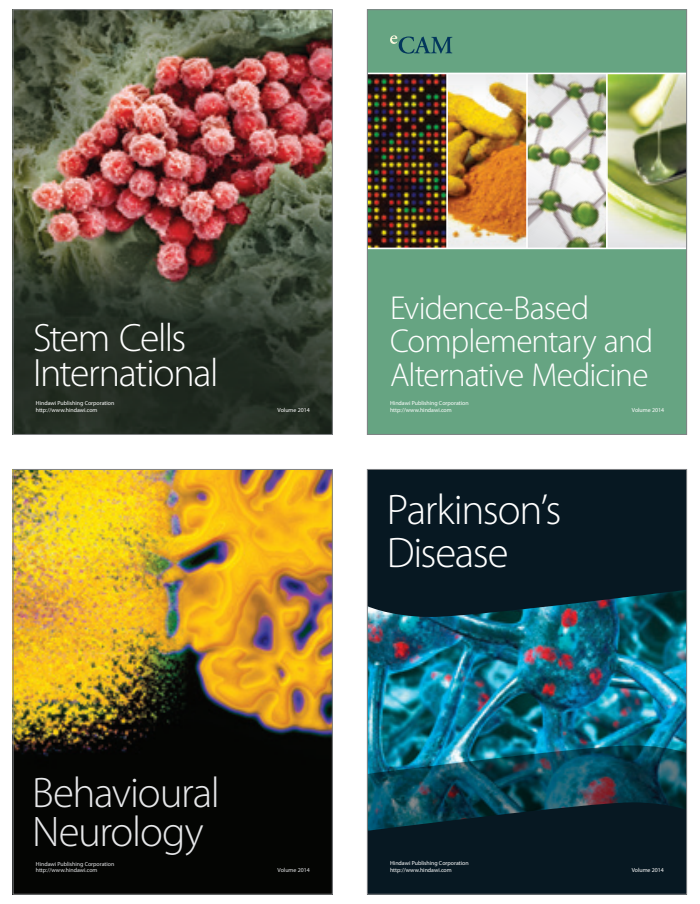
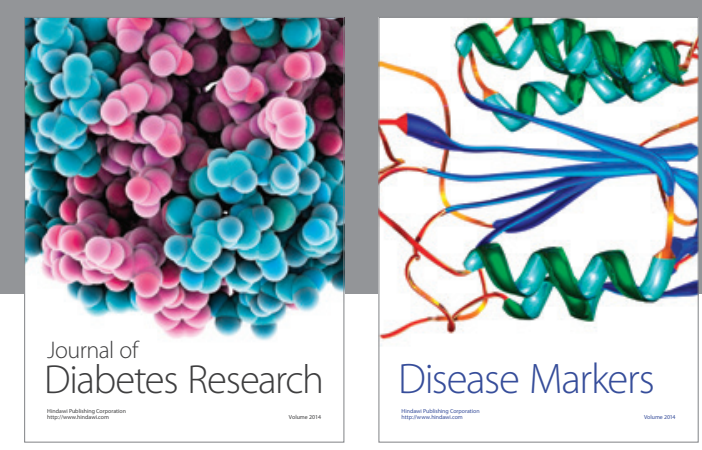

Disease Markers
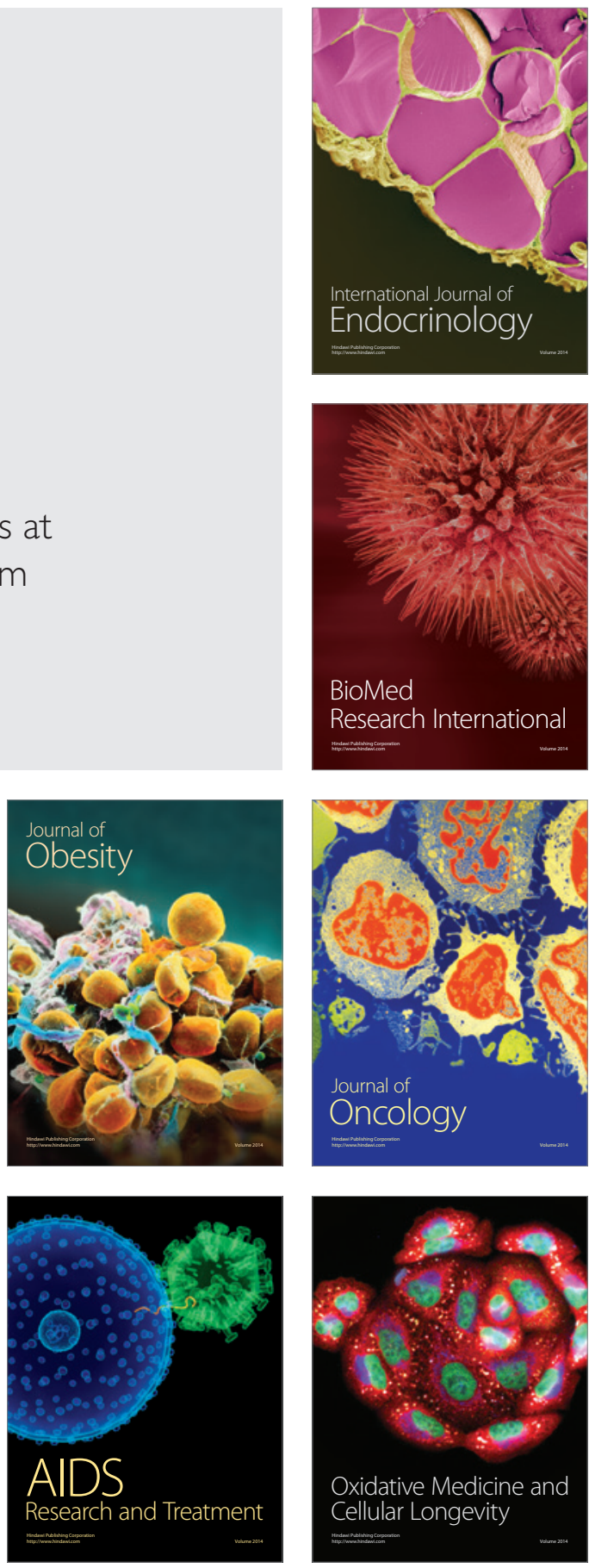